Int. J. Dev. Biol. 57: 677-687 (2013)

doi: $10.1387 / \mathrm{ijdb} .130285 \mathrm{dg}$

\title{
Connecting epithelial polarity, proliferation and cancer in Drosophila: the many faces of Igl loss of function
}

\author{
DANIELA GRIFONI*, FRANCESCA FROLDI" and ANNALISA PESSION \\ Dipartimento di Farmacia e Biotecnologie, University of Bologna, Italy
}

\begin{abstract}
Loss of cell polarity is a prominent feature of epithelial cancers. Several tumour-suppressor genes are indeed involved in establishing and maintaining a correct apical-basal polarity suggesting that a link exists between disruption of epithelial polarity and the control of cell proliferation. Nevertheless, the molecular basis of this link is only beginning to be unveiled. In Drosophila, the tumour suppressor gene lethal giant larvae (Igl) is widely used as a genetic tool in cancer modelling: its loss of function causes neoplastic growth of the imaginal tissues, larval epithelial organs from which adult structures originate. These mutant epithelia are characterised by loss of cell polarity and tissue architecture as well as hyperproliferation. We observed that in a clonal context, the ability of $I g /$ mutant cells to express their neoplastic potential correlates with the levels of the oncoprotein Myc, a master regulator of cell growth and proliferation. Malignant, polarity-deficient mutant cells upregulate Myc and are able to overcome the tumour-suppressive defences imposed by the surrounding wild-type tissue. How does the loss of Igl function induce an increase in Myc levels? The answer to this question came from the finding that $\mathrm{Lgl}$ is an upstream regulator of the Hippo pathway, a highly conserved signalling network that controls proliferation of epithelial cells and organ size. The core of this pathway responds to several upstream regulators and converges on the inhibition of a transcriptional co-factor, Yorkie, which, as we and others have shown, is a direct regulator of the myc promoter. In this review we discuss the key findings that contributed to the identification of this regulatory network that links cell polarity to cell proliferation control.
\end{abstract}

KEY WORDS: Drosophila, cell competition, Myc, Lgl, cancer

\section{Introduction}

The knowledge of the genetic basis of cancer is the groundwork on which researchers can build and verify their experimental hypotheses, hopefully leading to effective medical treatments. Cellular and animal models have deeply contributed to the acquisition of this knowledge, and the fruitfly Drosophila melanogaster has been recently used to investigate the genetic mechanisms underlying the behaviour of cancer cells growing in heterotypic backgrounds. Differently from what happens to mutant cells bearing a genetic arrangement identical to their neighbours, which behave in a stereotypical manner, the same cells growing in heterotypic contexts can indeed show diametrically opposite behaviours, from being eliminated from the tissue to growing faster and faster, overwhelming the adjacent populations. Such kind of genetic analysis, which is to date the most accurate way to model human tumourigenesis, accounts on the possibility in Drosophila tissues to generate single mutant cells which, while proliferating, are influenced by different chemical and physical stimuli depending on the surrounding microenvironment. To this purpose, mutations in tumour suppressor genes have been extensively used to induce cancer in different genetic contexts, and here we summarise recent advances in the field obtained from the study of $/ g /$ function in tumour biology.

\section{Igl and cancer}

lethal (2) giant larvae was the first tumour suppressor described in literature (Gateff, 1978). It is classified as neoplastic tumour

Abbreviations used in this paper: aPKC, atypical protein kinase $\mathrm{C}$; dlg, discs large; Hpo, hippo; JNK, c-jun N-terminal kinase; lgl, lethal giant larvae; scrib, scribble; Yki, yorkie.

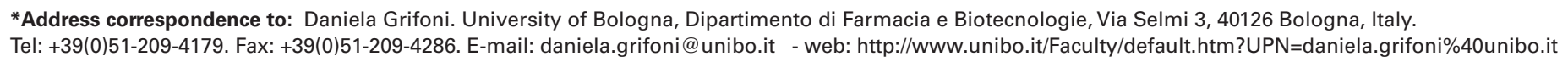

\#Present address: Peter MacCallum Cancer Centre, Melbourne, Australia

Accepted: 6 November 2013. Final, author-corrected PDF published online: 9 December 2013.

ISSN: Online 1696-3547, Print 0214-6282 
suppressor gene (nTSG) as its loss of function (LOF) causes malignant growth of Drosophila ectodermal derivatives: imaginal discs (larval epithelial structures which originate adult organs during metamorphosis) and the neuroblasts of the larval brain. As a result of $l g /$ mutation, these organs undergo loss of apical-basal (A/B) cell polarity and excessive proliferation, leading to severe alterations in tissue organisation. Mutant cells are unable to exit cell cycle and never differentiate, forming amorphous masses that lead to an extended larval period and pre-pupal lethality (Bilder, 2004). These tumourous masses are invasive, as they produce basement membrane-degrading enzymes, fuse with adjacent organs and become highly metastatic upon transplantation in adult naive hosts (Woodhouse et al., 1998; Beaucher et al., 2007a, Beaucher et al., 2007b).

Given the strong similarities between $/ g l$ tissues and human epithelial cancers, and the high degree of functional conservation (see below), Igl mutants have been extensively used as genetic tools for the investigation of the molecular basis of epithelial transformation (Froldi et al., 2008). The human genome encodes two Drosophila Lgl protein orthologues: Lgl-1 and Lgl-2 (also known as Hugl-1 and Hugl-2); several lines of evidence showing decreased expression or loss of $\mathrm{Lgl-1/2}$ in primary human tumours seem to indicate that they play a role in mammalian tumourigenesis. Indeed we and others showed that $L g /-1$ transcript results decreased or completely absent in a variety of human epithelial malignancies such as breast, lung, prostate, ovarian cancers and melanoma (Grifoni et al., 2004; Kuphal et al., 2006). Lgl-1 loss has also been implicated in colorectal cancer progression, where it was found to be associated with advanced stages and lymph node metastases (Schimanski et al., 2005); it is also correlated to reduced survival in glioblastoma (Korshunov et al., 2006), where its inactivation has been recently shown to be responsible for the maintenance of a population of undifferentiated cells named tumour initiating cells (Gont et al., 2013). Finally, the occurrence of aberrant splicing variants has been associated with hepatocellular carcinoma progression (Lu et al., 2009). This evidence strongly indicates that $\mathrm{lg} /$ human orthologues also function as tumour suppressor genes.

\section{Igl and cell polarity}

The plasma membrane of epithelial cells is subdivided into two functionally distinct domains, apical and baso-lateral domains, by means of epithelial cell junctions and protein complexes. The lateral domain interconnects neighbouring cells, while the apical domain forms a specialised surface usually not in permanent contact with other cells. This distinct polarisation along the apical-basal axis is essential for adhesion, communication, vectorial transport, permeability and morphogenetic properties of epithelia (Dow and Humbert, 2007) and its alteration is a hallmark of epithelial cancers (Wodartz and Näthke, 2007). Loss of A/B cell polarity is a prominent feature of $\mathrm{lg} /$ LOF phenotype (see above) and indeed, extensive genetic analysis in Drosophila has led to the notion that Lgl functions in a 'baso-lateral' protein complex, together with the products of two other nTSG with very similar LOF phenotypes, Scribble (Scrib) and Discs large (Dlg). This complex works in establishing and maintaining cell polarity by antagonising the activity of two other protein complexes: the Crumbs/Stardust/PATJ (apical) and the Bazooka/Par6/aPKC (sub-apical) complexes.

\section{The Crumbs/Stardust/PATJ complex}

This complex establishes the apical identity of polarised cells and is required for adherens junctions (AJs) formation both in Drosophila and mammalian epithelial cells. It consists of three main components: a transmembrane protein, Crumbs (Crb), and two adaptor proteins, Stardust (Sdt) and PATJ. Drosophila Crb is characterised by a large extracellular portion with thirty epithelial growth factor (EGF)-like and four laminin A G-domain-like repeats, and a small conserved cytoplasmic region. In mammals three homologous genes have been identified (CRB 1-3); they show tissue specific expression patterns (CRB3 is the most widely expressed in epithelial tissues), and high levels of sequence identity with Drosophila Crumbs are observed in the cytoplasmic domain. std encodes a MAGUK (Membrane-Associated with GUanylate Kinase domain) protein with a PDZ(PSD-95/Dlg/ZO-1), a SH3 (Src Homology region 3) and a GUK (GUanylate Kinase-like) domain which binds Crb intracellular domain. Similarly, CRB3 complexes with the PDZ domain of Std mammalian homologue Pals1 (Protein associated with lin seven 1). The third component is encoded by dpatj gene in Drosophila and two mammalian homologues, PATJ (Pals-Associated Tight Junction Protein) and MUPP1 (MUlti-PDZ domain Protein 1), are also known to interact with Crb intracellular portion (Dow and Humbert, 2007; Tervonen et al., 2011).

\section{The Bazooka/Par6/aPKC complex}

In Drosophila, below the Crumbs/Stardust/PATJ Complex, at the sub-apical region lies a complex composed of two scaffold proteins, Bazooka (Baz) and Par6, both containing PDZ domains as well as other protein-protein interaction motifs, and an atypical Protein Kinase C, aPKC. Genetic analysis has revealed that they are mutually dependent for proper localisation and zonula adherens (ZA) formation. In mammals one Baz homologue (Par3), three Par6 homologues (Par6 $\alpha, \beta$ and $\gamma$ ) and two aPKC homologues (aPKC $\lambda / \mathrm{t}$ and $\mathrm{aPKC} \xi$ ) have been found with differential expression patterns but mostly redundant functions. In mammalian cells this complex localises at tight junctions and is required for AJs formation as it is in Drosophila (Dow and Humbert, 2007; Tervonen et al., 2011).

\section{The Scribble/Discs large/Lethal giant larvae complex}

In Drosophila, scrib, dlg and IgInTSGs show very similar LOF phenotypes as well as a strong genetic interaction. Indeed, genetic analysis demonstrated that they act in a common pathway linking cell polarity and cell proliferation control in epithelial cells(Bilder and Perrimon, 2000). They all encode scaffolds rich in protein-protein interaction domains. Scribble belongs to the LAP (Leucine-rich repeats And PDZ domain) family and has four PDZ domains at the C-terminus and sixteen LRR (Leucine-Rich Repeats) at the $\mathrm{N}$-terminus; it is encoded by a single gene both in Drosophila and vertebrates. Dlg is a MAGUK protein and contains three PDZ, an SH3 and a GUK domain. Several mammalian orthologues of Drosophila dlg have been identified so far. lethal giant larvae encodes a protein, Lgl, rich in WD40 repeats, predicted to fold into two $\beta$-propeller domains at the $\mathrm{N}$-terminus. Lgl mammalian orthologues, Lgl-1 and Lgl-2, also contain WD40 repeats and have distinct expression patterns (Dow and Humbert, 2007; Tervonen et al., 2011). Fly and human proteins show the significant global sequence similarity of $62.5 \%$ if conservative aminoacid changes are taken into account, and we found conclusive evidence of the 
functional conservation between the two proteins in the full rescue of the Drosophila Igl mutant by the human Lgl-1 cDNA (Grifoni et al., 2004). Analogous rescuing ability has been demonstrated for rat DIg (Thomas et al., 1997) and human Scrib (Dow et al., 2003). In Drosophila it has been demonstrated that the three proteins are mutually dependent for correct localisation (Bilder and Perrimon, 2000), although direct physical interactions have never been proven. Dig and Scrib localise at the membrane cortex, at Drosophila septate junctions (SJs). Lgl colocalises with Dlg and Scrib at SJs but it is also found in the cytoplasm. In neuronal synapses Scrib has been shown to bind DIg via a protein named GUK Holder. In mammalian epithelial cells they are also localised at the basolateral domain of the plasma membrane and, similarly to the fly counterparts, the exact nature of their physical interaction has yet to be established; so far direct binding has only be proven for Scrib and Lgl-2 (Kallay et al., 2006).

The mutually exclusive activity of these three complexes is required for the correct formation and positioning of cell junctions, which in turn provide cells with a correct apical-basal and cytoskeletal structure (Dow and Humbert, 2007). The mechanism through which the Baz/Par6/aPKC and the Scrib/Dlg/Lgl complexes regulate each other was initially investigated in Drosophila neuroblasts, the larval neuronal progenitors (Betschinger et al., 2003). These cells do not have cell junctions but require a compartmentalisation of membrane domains in order to perform asymmetric cell division. These membrane complexes are required for proper positioning of cell fate determinants that will differentially segregate into the daughter cells giving origin to a new stem cell (self-renewal) and to a ganglion mother cell (GMC), the neuron/glia precursor. Failure to segregate cell fate determinants due to Ig/LOF results in excessive self-renewal and thus abnormal expansion of the neuroblast population (Wodarz, 2005). It was demonstrated that Lgl localisation at the plasma membrane depends on its phosphorylation in conserved residues by aPKC of the Baz complex (Betschinger et al., 2003). Phosphorylated Lgl assumes an autoinhibited conformation in which protein interaction domains are masked and is thus excluded from the cortex. Lgl in turn counteracts aPKC activity by sequestering it in an inactive Lgl/aPKC/Par6 complex from which Bazooka is excluded (Betschinger et al., 2005). Targeting of aPKC to the entire cell cortex reproduces Igl phenotype: asymmetric cell division is impaired leading to an excess of self-renewal and abnormal increase in neuroblast population (Lee et al., 2006). Similarly, in epithelial tissues, cortical spreading of aPKC activity causes Lgl inhibition in the baso-lateral domain leading to tumourous growth, similarly to what is observed for lglindividuals (Grifoni et al., 2007). Reduced aPKC levels suppress Igl phenotype in the imaginal discs (Rolls et al., 2003) and a non-phosphorylatable form of Lgl completely fails to rescue the mutant phenotype in embryos lacking both maternal and zygotic Igl function (Hutterer et al., 2004). The Crb complex is recruited by the Baz complex at the apical domain and seems to further antagonise the activity of the Lgl complex by blocking its spreading along the lateral membrane domain. Crb is phosphorylated by aPKC and this event is required for its correct apical localisation (Dow and Humbert, 2007). As expected from the high level of functional conservation, mammalian Lgl-1 and Lgl-2 are also excluded from the apical domain due to aPKC phosphorylation and are able to bind Par6 and aPKC preventing their association with Par3 and thus the baso-lateral spreading of apical complexes (Dow and Humbert, 2007). Moreover, we found that Lgl-1 subcellular localisation seems to play a crucial role in human cancer, as its cytoplasmic enrichment correlates to aPKC lateral spreading and cancer progression in ovarian carcinomas (Grifoni et al., 2007), mirroring what is observed in Drosophila Igl epithelial cancers. Another interesting parallel with fly lg/ LOF phenotype can be found in a mouse $\mathrm{Lgl-1}$ knock-out (KO) model. Severe brain dysplasia, caused by the abnormal expansion of the progenitor cell population, is observed at birth. These cells are unable to exit cell cycle and differentiate, and form rosette-like structures, similar to the neuroblastic rosettes found in human pediatric tumours (Klezovitch et al., 2004).

\section{Lgl, cell proliferation and the Hippo pathway}

Understanding how disruption of cell polarity and control of cell proliferation are linked would represent a significant advance in the comprehension of the molecular basis of epithelial cancer development. Originally, Ig/mutant tissue overgrowth was hypothesised to be a direct consequence of loss of cell polarity caused by delocalisation of signalling molecules and simultaneous deregulation of several different pathways (Lee et al., 2006). Nevertheless, several lines of evidence have demonstrated a specific signalling function of the $\mathrm{Dlg} / \mathrm{Lgl} / \mathrm{Scrib}$ module in proliferation control. First evidence came from the identification of $I g l$, scrib and $d l g$ in a screen for dominant suppressors of a hypomorphic mutation of cyclin E, a key regulator of G1-S phase transition (Brumby et al., 2004), implying a direct role in negative regulation of cell cycle. Indeed lgl clones in the eye disc (see below) show ectopic Cyclin E expression and thus ectopic S-phases without a complete disruption of apicalbasal polarity (Grzeschik et al., 2010), demonstrating that growth deregulation is not an immediate consequence of polarity loss.

The link between $\mathrm{Ig} /$ and cell proliferation control was however finally established with the demonstration that the proliferative defects in the eye disc described above were due to the deregulation of the Hippo (Hpo) pathway (Grzeschik et al., 2007), a very conserved signalling network that plays a central role in the control of epithelial tissue growth (Huang et al., 2005; Dong et al., 2007; Halder and Johnson, 2011). The Hpo pathway is composed of two core kinases, Hpo and Warts (Wts), the adaptors Salvador (Sav) and Mob As a Tumour Suppressor (Mats) and the transcriptional co-activator Yorkie (Yki), and it is modulated by numerous upstream factors among which the cytoskeletal proteins Expanded (Ex) and Merlin (Mer) and the atypical cadherins Fat (Ft) and Dachsous (Ds). When the pathway is active, Hpo can phosphorylate and activate Wts which in turn phosphorylates Yki sequestering it in the cytoplasm (Fig. 1A); on the other hand, upon its inactivation unphosphorylated Yki can translocate into the nucleus and, binding to different tissue-specific partners, activate the transcription of its target genes involved in cell growth, proliferation and resistance to apoptosis such as cyc E, dIAP1 (Drosophila Inhibitor of APoptosis 1) and the miRNA bantam (Halder and Johnson, 2011) (Fig. 1B). Yki is thus a growth promoter, whereas the upstream components act as tumour suppressors by antagonising the growth-promoting activity of Yki. Mutations in each of the known genes encoding components of the Hpo pathway are per se incapable to give rise to neoplastic phenotypes; rather they originate cells which proliferate into hyperplastic masses (Hariharan and Bilder, 2006); for a malignant growth to occur, a functional cooperation between loss of cell polarity and hyperplasia seems thus to be required. 
Lgl was first shown to take part in the control of this pathway in the eye imaginal disc: in lgl mutant cells, an upregulation of Hpo pathway target genes such as cyc $E$ and $d I A P 1$, as well as genes belonging to the negative feedback loops such as ex, was indeed observed; consistently, in lgl cells Yki was found also in the nucleus and the levels of the phosphorylated form were reduced (Grzeschik et al., 2007) (Fig. 1C). Removal of one copy of yki partially reduced $\mathrm{Hpo}$ target genes upregulation as well as the ectopic S-phases phenotype previously described (Grzeschik et al., 2007), indicating that Yki activity is required for $/ g /$ proliferative defects. Yki activation in Igl cells seems to be due to Hpo mislocalisation and to the putative formation of an inactive complex with RASSF (Ras associated factor), another regulator of the pathway, also mislocalised in mutant cells (Grzeschik et al., 2010) (Fig.
1C). The same effect is observed when an active form of aPKC is expressed; since Lgl and aPKC are mutually exclusive (see "Lgl and cell polarity" paragraph), when aPKC localises at the whole cell cortex, $\mathrm{Lgl}$ is completely released from the membrane, thus phenocopying $\mathrm{lg} /$ mutation. Crumbs, a protein of the apical polarity complex, has also been placed upstream of the Hippo signalling. Upon its overexpression, the authors observe the delocalisation of Expanded from the apical to the lateral cell domain; since Expanded binds Yorkie and fastens it to the cell cortex (Badouel et al., 2009), it is plausible that its removal from the apical region is responsible for Yorkie activation (Grzeschik et al., 2010; Ling et al., 2010). A similar effect has been observed in the wing disc: upon Crumbs overexpression, the protein Expanded resulted either delocalised or reduced in level (Chen et al., 2010; Ling et al., 2010; Robinson

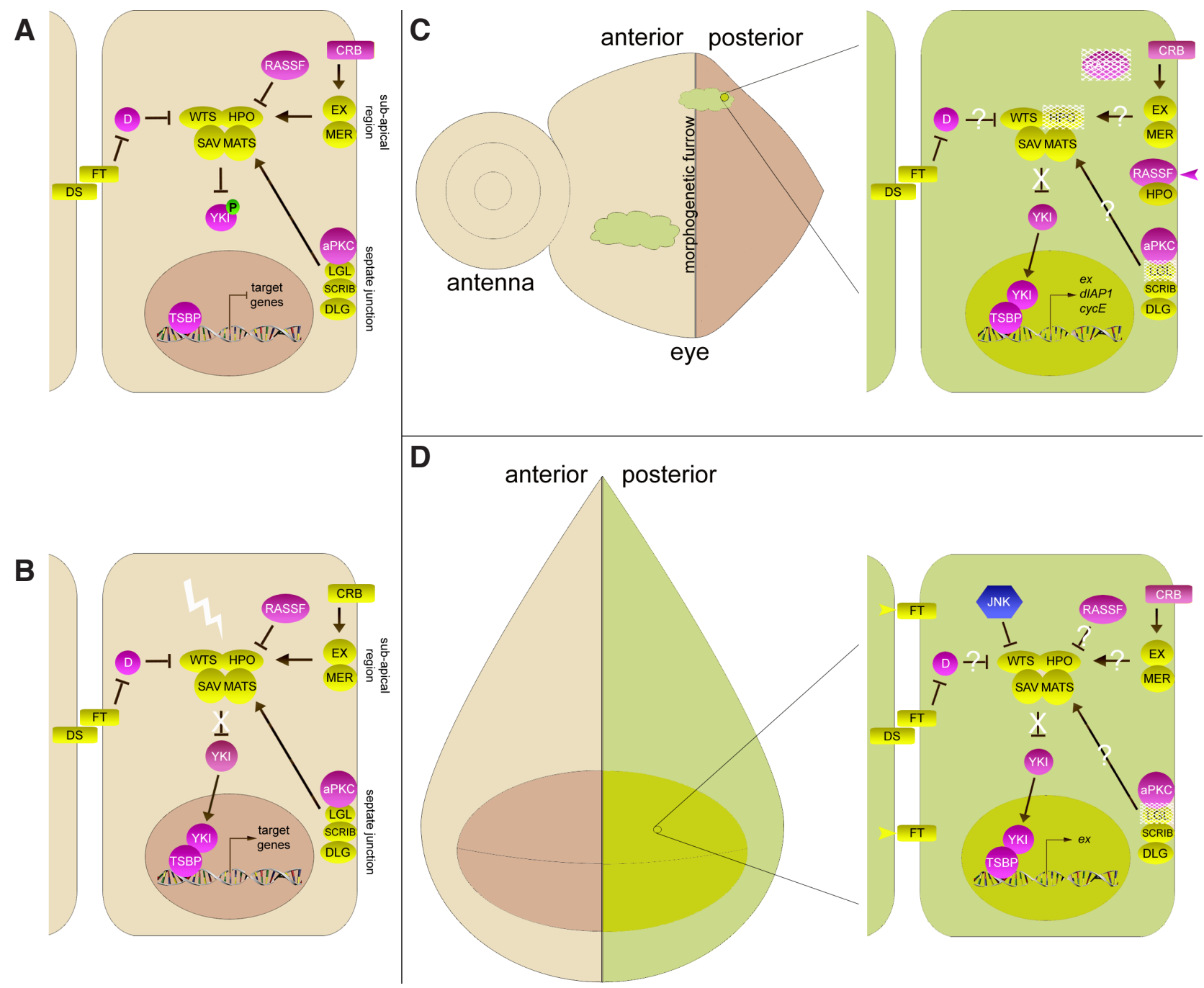

Fig. 1. Hippo pathway deregulation upon Igl loss of function in the imaginal epithelia. (A,B) Schemes depicting the Hippo pathway in an active state (A) and upon any event causing its deregulation (B). The main members cited in the text are represented. (C) An eye-antennal disc in which lgl mutant clones (green) have been generated. Igl mutation in this context provokes RASSF/Hpo mislocalisation at the baso-lateral membrane (pink arrowhead) and Yki nuclear enrichment. (D) A wing disc in which Igl knockdown has been induced in the posterior compartment (green). In this context, Ft mislocalises at the whole cell cortex (yellow arroheads) and deregulation of the Hippo pathway is JNK-dependent. Abbreviations: CRB, Crumbs; RASSF, Ras-associated factor; EX, Expanded; MER, Merlin; WTS, Warts; HPO, Hippo; SAV, Salvador; MATS, Mob as a tumour suppressor; D, Dachs; FT, Fat; DS, Dachsous; YKI, Yorkie; aPKC, atypical Protein kinase C; LGL, Lethal giant larvae; SCRIB, Scribble; DLG, Discs large; TSBP, Tissue-specific binding partner. In pink, proteins which overexpression causes pathway deregulation; in yellow, proteins which loss causes pathway deregulation. Details are found in the main text. 
et al., 2010).

lgl-dependent regulation of Yki has also been observed in the wing imaginal disc but it was proposed to occur through a different mechanism. Igl depletion-dependent tumours were generated by specifically knocking down $l g l$ transcript in the posterior compartment of the wing disc leading to overgrowth and loss of cell polarity (Sun and Irvine, 2011). In these posterior cells Ft resulted mislocalised at the entire cell cortex, Yki was mainly found in the nucleus and Hpo pathway reporter genes such as ex were upregulated (Fig. 1D). Indeed knockdown of Yki or overexpression of Wts in this context blocked the overgrowth and resulted in discs with reduced posterior compartment and high levels of cell death, suggesting that Yki activity is required for growth and survival of /gl-depleted cells. Interestingly Yki activation was found to be due to JNK (c-Jun N-terminal kinase) signalling (Sun and Irvine, 2011) (Fig. 1D), an evolutionarily conserved stress-induced MAPK cascade that has roles in multiple cellular processes including proliferation, differentiation, morphogenesis, and most of all, apoptosis, and has been implicated in several aspects of tumour development in Drosophila and humans (Ryoo et al., 2004; Igaki et al., 2006; Wagner and Nebreda, 2009; Chen, 2012).

Two explanations have been proposed to account for the differences in Yki regulation upon $/ g /$ depletion in the eye $v s$ wing imaginal discs: first, in the experimental conditions employed in the wing disc cell polarity was lost, whereas this was not the case in the eye disc; second, wing and eye discs seem to have a different sensitivity to JNK signalling since its direct activation is able to regulate Yki in the wing disc only (Sun and Irvine, 2011). Ig/ may thus regulate cell proliferation by influencing the Hpo pathway in a tissue-specific manner through JNK-dependent and independent pathways. scribloss of function however induces JNK-independent impairment of the Hpo pathway in both the eye and wing imaginal discs (Dogget et al., 2011). It thus seems that the crosstalk between cell polarity proteins, JNK signalling and the Hpo pathway are complex and possibly context-dependent and further work is needed to clarify this. In a recent paper, genetic evidence has been provided suggesting that Scrib acts downstream of $\mathrm{Ft}$ and that it is required by this latter for the interaction with Ex and Dachs (D), an unconventional myosin that participates in the regulation of the Hpo pathway downstream of $\mathrm{Ft}$ (Verghese et al., 2012).

Similarly to what has been demonstrated for $I g /$ and scrib LOF phenotypes, deregulation of the Hpo pathway also seems to contribute, at least in part, to the overgrowth that characterises the oncogenic cooperation between activated Ras/Raf and polarity gene loss (Dogget et al., 2011, Menéndez et al., 2010, Chen et al., 2011). In 2003, two pivotal studies were published showing that constitutive activation of Ras signalling rescues scrib, $I g l$ and $d l g$ mutantcells viability and induces in mutant cells massive overgrowth and acquisition of striking invasive capabilities (Brumby and Richardson, 2003; Pagliarini and Xu, 2003). More recently, Dogget and colleagues found that Yki target genes were upregulated in scrib; RafAct $^{\text {(or Ras }}{ }^{V 12}$ ) tumours in the eye imaginal disc and inhibition of Yki activity significantly reduced tumour growth. However, despite reduction of the tumourous mass, mutant clones were still able to invade and differentiation remained blocked, indicating that $\mathrm{Hpo}$ pathway impairment does not contribute to these phenotypes. Moreover, the fact that the growth of these clones was not totally abrogated by blocking Yki function suggests that other pathways may be involved in driving scrib; Raf ${ }^{\text {Act }}$ cells clonal expansion in this context (Dogget et al., 2011). In another study, analysis of large overgrown and fast-proliferating $/ g l ;$ Ras $^{V 12}$ clones in the wing disc revealed an evident Yki nuclear staining and, accordingly, a strong upregulation of its target genes. The authors did not test whether Yki was required for the overgrowth of $l g l ; R^{2}{ }^{v 12}$ clones but showed that its expression within $/ g /$ clones is sufficient to promote it (Menéndez et al., 2010). Similarly, scrib; Ras ${ }^{V 12}$ clones in the wing disc also showed upregulation of Yki target genes and Yki overexpression was able to promote overgrowth of scribmutant cells (Chen et al., 2011).

\section{Regulation of the Hpo pathway by the Scrib/Dlg/Lgl module in vertebrates}

Deregulation of several members of the Hpo pathway has been found associated with proliferative disorders in humans (Harvey et al., 2013), but clear evidence of a functional interaction between the Scrib/Dlg/Lgl module and the Hpo pathway in vertebrates is only beginning to appear in literature, and the majority of studies so far reported focus on scrib because a single orthologue of this gene is present in vertebrate genomes. As an example, Fat-1 and Scrib have been shown to act in a common signalling cascade during zebrafish pronephros development, possibly through a direct interaction, as human Scrib was shown to bind both mouse Fat-1 (via its PDZ-binding site) and DrosophilaFat in immunoprecipitation assays (Skouloudaki et al., 2009). In a more recent study, Cordenonsi and colleagues showed that the transcriptional coactivator TAZ (a Yki human orthologue) is required for self-renewal and tumour initiation of human breast epithelial cancer cells and that its increased activity is associated with a more malignant phenotype. Interestingly, they found that Scrib forms a complex with TAZ that is required for its inhibitory association with the Hpo core kinases LATS (Wts human orthologue) and MST. As a consequence, Scrib loss/mislocalisation triggers TAZ oncogenic activity (Cordenonsi et al., 2011).

\section{Igl, cell competition and Myc}

In the past decade a key concept has strikingly emerged in the field of cancer biology: cancer can not be considered as a cellautonomous disease; progression towards malignancy is instead unavoidably influenced by the crosstalk between cancer cells and their microenvironment (Pietras and Östman, 2010; McAllister and Weinberg, 2010). A paradigm of this concept can be found in the analysis of $\mathrm{g} /$ clonal phenotype: when patches of mutant tissue grow in a wild-type background, they behave remarkably differently compared to the whole mutant animal, where neoplastic growth and loss of cell polarity are invariantly observed. In the eye imaginal disc, $\mathrm{lg} /$ clones show ectopic proliferation but maintain apical-basal cell polarity. Overall clonal size is however not affected since increased cell death is also observed (Grzeschik et al., 2007). The differences between $/ g /$ clones and whole mutant tissues are even more striking in the imaginal wing disc: mutant cells are rapidly eliminated by apoptotic death and do not contribute to the adult organ almost at all. We demonstrated that $/ g /$ mutant cells elimination in this organ is attributable to the phenomenon of cell competition (Froldi et al., 2010).

Cell competition is a mechanism of short-range cell-cell interaction firstly described in Drosophila imaginal wing discs about 40 years ago (Morata and Ripoll, 1975), which consists in the removal 
during development of viable but slow-dividing, unfit or damaged cells (losers) by the surrounding faster growing populations (winners), ensuring that the adult organ reaches proper size. It occurs in distinct, inter-dependent phases (Lolo et al., 2012): first, a loser cell is produced by a mutational event that modifies its proliferation or metabolic rate, next the winner cells kill the losers, dying cells are then basally extruded from the epithelium, apoptotic debris is removed by competent cells and winner cells over-proliferate to compensate for cell loss (Fig. 2 A-C). It was initially proposed that winner cells were also responsible for the engulfment of loser cell residues (Li and Baker, 2007), but it was recently demonstrated that clearance is rather carried out by recruited hemocytes (Lolo et al., 2012). Cell competition was initially observed analysing a group of dominant mutations called Minute $(M)$ that concern various ribosomal protein genes. These mutations are recessive lethal and display a dominant growth defect: $M^{+/-}$cells are viable but have a slow growing rate and consequently $M^{+/-}$flies are of normal size but their development is delayed with respect to wild-type counterparts. However, if mitotic clones of $M^{+/}$cells are generated in a wild-type wing imaginal disc tissue, they are eliminated by apoptosis. Extra proliferation in the wild-type tissue occurs to replace outcompeted cells, the total number of which in the developing tissue remains unchanged and no morphological alterations are observed in the resulting organ (Gallant, 2005). Interestingly, Tyler and colleagues (Tyler et al., 2007) found that mutations in several genes belonging to the Hpo pathway were able to protect $\mathrm{M}^{+-}$cells from being outcompeted in a wild-type background and even to provide them with competitive capabilities, as indicated by active Caspase 3 staining visible outside the mutant clones (Tyler et al., 2007), demonstrating the involvement of this pathway in the phenomenon of cell competition.

lgr mutant cells, despite being unable to exit cell cycle, proliferate at a slower rate compared to the wild-type counterparts (Bilder, 2004; Froldi et al., 2010) and, when surrounded by wild-type tissue, are found to undergo apoptotic cell death mediated by the activation of JNK signalling (Froldi et al., 2010; Tamori et al., 2010). Igl mutant
Fig. 2. Cell competition and Igl mutant cell phenotypes. (A-C). The main phases of cell competition. An imaginal epithelium is represented, with the ventral (V) surface up and the dorsal (D) down. PM: peripodial membrane, a squamous epithelium that coats the ventral surface of all imaginal discs; DP: disc proper, formed by the columnar epithelium; BM: basement membrane; $A$ : apical side of the DP; $B$ : basal side of the DP. (A) A cell with a mutation in genes involved in cell proliferation, cell growth or cell metabolism appears in the epithelium (loser, green). (B) The loser cell is killed by the adjacent wild-type cells (brown) and basally extruded from the epithelium in the form of apoptotic bodies. (C) Cellular debris is removed and extra-proliferation occurs in the winner cells which replace the loser. (D,E) Myc transcript and protein in lgl mutant clones. (D) Igl' clones in a wild-type background lose the competition and are eliminated from the epithelium. Myc transcriptional activity is normal but Myc protein does not accumulate within mutant clones. (E) Igl; Myc clones win the competition and overgrow with respect to the wild-type neighbours. Myc transcript and protein are both upregulated. (F-H) Relationship between Myc pattern and Igl clonal behaviour. (F) Myc pattern in the wing disc: Myc protein is enriched in the distal region (wing pouch) and very low in the proximal territories (hinge and pleura), where lgl clones overexpressing Myc are able to overgrow and form tumourous masses (G). Despite Myc overexpression, Igl mutant clones are not able to grow in the wing pouch region (H). See main text for more details.
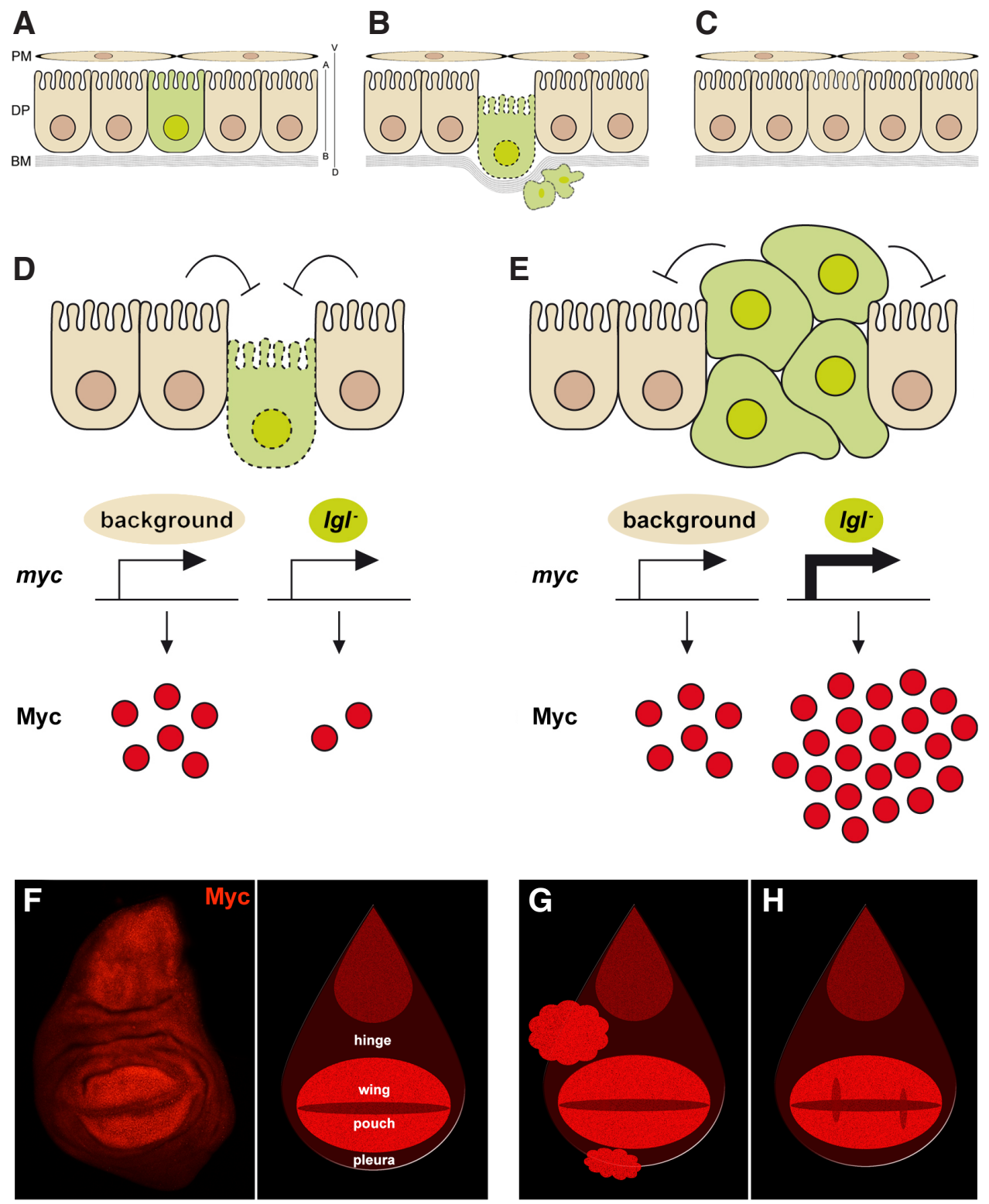
cell elimination was found to be more efficient in the distal region of the wing disc, known as wing pouch, where cell competition is known to be the strongest. Moreover, as expected when competitive interactions take place, wild-type twins of $/ g l$ clones were found to overgrow to compensate for mutant cell loss (Froldi et al., 2010). When generated in a non-competitive Minute background (see above), Igrcells were able to overgrow and form tumourous masses characterised by invasive behaviour and cell polarity loss, like the whole mutant tissue, further demonstrating the involvement of cell competition in Ig/mutant cell clonal behaviour (Froldi et al., 2010).

In addition to ribosome impairment, mutations in genes responsible for cell growth have also been found associated with cell competition, such as the Decapentaplegic (Dpp)/Transforming Growth Factor $\beta$ (TGF $\beta$ ) pathway, for which cells compete to escape apoptotic death (Moreno et al., 2002). In recent years, the protooncogene myc has been strongly implicated in this phenomenon in Drosophila (de la Cova et al., 2004; Moreno and Basler, 2004). Clones bearing hypomorphic myc mutations, viable in a homotypic environment, were found to be eliminated by non-autonomous cell death when generated in a wild-type imaginal disc (Johnston et al., 1999). In 2004 two papers were published in which it was clearly demonstrated that cell competition is not simply caused by cellular defects associated with myc loss because, as it was shown, also wild-type cells are out-competed if surrounded by Myc-overexpressing cells, and that it is instead triggered by a sharp difference in Myc protein levels between adjacent populations (de la Cova et al., 2004; Moreno and Basler, 2004). de la Cova and colleagues showed that clones overexpressing Myc were significantly larger than control clones, due to promotion of cellular growth; however, sibling clones generated in recombination events were smaller than control siblings. They also showed that wild-type cells appeared to be subject to competition only if they lied within about eight cell diameters away from Myc-expressing cells and in the same developmental compartment (de la Cova et al., 2004); it was indeed later suggested that cell competition is mediated by soluble factors (Senoo-Matsuda and Johnston, 2007). Using a myc tandem duplication, similar results were obtained by Moreno and Basler (Moreno and Basler, 2004). Sibling clones were generated that were composed of cells with four $(4 \mathrm{xmyc})$ or two copies $(2 x m y c)$ of the endogenous myc gene. Interestingly, not only $4 x m y c$ clones were significantly larger than their $2 x m y c$ wild-type siblings, but they were also larger than control clones that were induced simultaneously in different individuals in which all cells carried four copies of myc. Likewise, clones carrying two copies of myc were not only smaller than their $4 x m y c$ siblings, but also smaller than control clones growing in a background where all cells had two copies of $m y c$, demonstrating that clonal growth strongly depends on cellular environment.

We found that $\mathrm{lg} /$ clones express much lower levels of Myc compared to the background, and this difference in Myc expression triggers /g/mutant cell elimination. Myc down-regulation in /g/ clones occurs at the post-transcriptional level, as a myc promoter reporter results active in mutant cells (Froldi et al., 2010) (Fig. 2D). The differences in $\mathrm{lg} /$ cell removal efficiency in the distal vs proximal regions of the wing disc correlate with Myc pattern: the protein is highly expressed in the wing pouch (distal) and very low in the hinge/ pleura (proximal) (Fig. 2F) where, as a consequence, Myc gradient between mutant and wild-type cells is reduced and cell competition is less fierce. Experimental overexpression of Myc in $\mathrm{lg} /$ mutant clones not only rescued their viability but promoted their malignant growth (loss of cell polarity and invasiveness) in proximal regions (Fig. $2 \mathrm{E}, \mathrm{G}$ ), whereas in the wing pouch Myc protein accumulation was found to be prevented by a still-uncharacterised mechanism and $\mathrm{lgl}$; Myc clones were thus eliminated anyway (Froldi et al., 2010) (Fig. 2H). Of note, isolated $/ g l ; R^{\prime} s^{V 12}$ clones were also found to undergo cell death in the wing pouch region (Menéndez et al., 2010) despite their well-known proliferative advantage. We suggest, based on our unpublished data, that the Igl-dependent Myc degradation we observed in the most central region of the wing pouch can counteract its accumulation induced by Ras activation (Prober and Edgar, 2002), impinging on the intrinsic transforming abilities of $/ g l ;$ Ras $^{V 12}$ cells. Further evidence of Myc involvement in lgl cells clonal behaviour came from the observation that overgrown and invasive lgl clones generated in a Minute background invariantly showed Myc upregulation and mycknock-down in these cells completely suppressed the tumourous phenotype (Froldi et al., 2010). Notably, Myc effect on Igl clonal behaviour seems very specific, as activation of a growth-promoting pathway that however failed to increase Myc levels within mutant cells, such as PI3K, was unable to promote their neoplastic growth (Froldi et al., 2010).

A different clonal behaviour with respect to the whole mutant phenotype is also a well-known feature of scribLOF: in the eye disc, clones lose polarity and overproliferate but very little mutant tissue is recovered in the adult eye as it is removed during development by JNK-mediated apoptosis. Interestingly, also in this case, cell death is induced in a non-autonomous manner by the surrounding wild-type tissue since upon its removal scrib clones viability is rescued (Brumby and Richardson, 2003). The mechanism described by Igaki and colleagues for JNK non-autonomous activation in scrib or dlg mutant clones was named Intrinsic Tumour Suppression (ITS), which consists in the endocytic activation of Eiger (Egr), the Drosophila TNF (Tumour Necrosis Factor), a known activator of the JNK pathway (Igaki et al., 2009). scrib- or dlg clones generated in an egr null background no longer die but overgrow and develop into tumours; the same effect was observed in the wing imaginal disc. Mutant cells were found to have increased endocytic activity and Egr was mislocalised and enriched the endocytic vesicles. Egr localisation correlated with intense phosphorylated - and thus activated - JNK staining. Indeed inhibition of endocytosis by means of a dominant negative form of Rab5 (an early endosomal marker) abolished JNK activation and mutant clones elimination, allowing tumourous growth. Ablation of surrounding wild-type tissue prevented endocytosis upregulation and Egr/JNK-dependent death of scrib cells (Igaki et al., 2009). Nevertheless, an involvement of cell competition in the elimination of scrib mutant cells has also been suggested based on the observation that a reduction of fitness in the surrounding wild-type cells (that is to say a Minutebackground) prevented scrib- cells elimination and promoted the formation of large proliferating clones (Chen et al., 2011).

Cell competition and ITS seem thus to be functionally related mechanisms triggered in opposing cells by different molecules but operating through the common JNK pathway (Vidal, 2010). Regarding Igl $^{-}$cells elimination, ITS seems not to be involved in the wing pouch region, where inhibition of endocytosis neither prevented mutant cells elimination nor JNK activation. Similarly, knock-down of egr had no effect on $/ g /$ mutant clone growth and did not prevent JNK signaling activation, suggesting that this latter functions independently of egr in this context (Froldi et al., 2010). 
On the other hand, inhibition of ITS in the proximal regions resulted in moderate overgrowth indicating that ITS and cell competition are likely to be involved in the elimination of $l g l$ mutant cells in complementary regions. Of note, also upon ITS inhibition, Igl proliferation is accompanied by an increase in Myc protein levels (Froldi et al., 2010).

The competitive traits shown by the Hpo pathway mutant cells (see above) have also been recently explained by the identification of myc as a target of this pathway (Ziosi et al., 2010, Neto-Silva et al., 2010). Indeed we were able to demonstrate that Myc upregulation is responsible for Hpo mutant or Yki-overexpressing clones competitive behaviour, as their overgrowth was drastically reduced if they were generated in a Myc-overexpressing background (Ziosi et al., 2010).

\section{Cell competition in mammals}

Myc expression is deregulated in a wide range of human cancers and is often associated with aggressive, poorly differentiated tumours (Albihn et al., 2010). It is thus becoming increasingly evident that Myc-induced cell competition could play a role in cancer development (Moreno, 2008; Baker and Li, 2008; Levayer and Moreno, 2013). Clones of cells expressing high Myc levels could expand at the expenses of the surrounding normal cells, without generating morphological changes. Further, expansion may increase the probability of accumulation of other mutations in subsets of cells that would confer new oncogenic properties to their descendants, as predicted by the field cancerisation theory (Rhiner and Moreno, 2009). On the other hand, cell competition may represent a mechanism of defence that tumour cells need to overcome in the very early steps of cancer onset in order to survive within the tissue (Moreno, 2008). Evidence exists that a phenomenon akin to cell competition is conserved also in mammals. It has been shown in mice that a deletion within the Rpl24 riboprotein gene significantly impairs ribosome biogenesis and results in decreased rates of protein synthesis and proliferation, clearly mirroring Drosophila Minute phenotype. Heterozygous mutant cells, while viable in a homotypic environment, giving rise to almost normal mice, are indeed out-competed by wild-type cells in chimeric blastocysts (Oliver et al., 2005). Another example is given by rat liver progenitors transplants: under certain conditions transplanted cells can overproliferate and induce cell death of the host cells to an extent that the entire liver is repopulated by donor-derived cells (Oertel et al., 2006). Compelling evidence of cell competition occurring in mammalian cell cultures has been produced in two recent papers (Tamori et al., 2010; Norman et al., 2012): inducible cell culture systems have been employed to demonstrate that such non-cell autonomous phenomenon is conserved. Tamori and colleagues knocked down the Lgl interactor Mahjong (that they proved to be involved in $/ g /$-mediated cell competition in Drosophila) in Madin-Darby canine kidney epithelial cells and showed that Mahjong-deficient cells undergo apoptotic cell death only when surrounded by wild-type cells (Tamori et al., 2010). Similar results were obtained by Norman and colleagues upon Scrib knockdown in the same cell line: the authors demonstrated that while Scrib knockdown cells were viable when surrounded by cells of the same kind, they died and were apically extruded in the presence of wild-type cells (Norman et al., 2012). Clear evidence of Myc-induced cell competition in mammals akin to that described in Drosophila epithelia has been finally obtained in the mouse embryo. Inducing functional genetic mosaics in the mouse, Clavería and colleagues were indeed able to demonstrate that an imbalance in Myc levels in the epiblast triggers the expansion of Myc overexpressing cells at the expenses of the cells with lower Myc levels, which are eliminated by apoptosis without impairing morphogenesis (Clavería et al., 2013). In addition, the authors found that wild-type cells forming the early embryo are heterogeneous in Myc content during normal development and endogenous cell competition refines the final epiblast selecting cells with higher Myc levels (Clavería et al., 2013). In a parallel study, Sancho and colleagues showed that defective embryonic stem cells undergo apoptosis during embryo development and that this mechanism depends on the establishment of differential c-Myc levels throughout the embryo (Sancho et al., 2013). Cell competition thus appears to be a conserved biological phenomenon through which developing tissues shape their final pool of cells. Strict evidence is however still missing about a role for Myc-induced cell competition in mammalian cancer. In mice intestinal crypts, loss of APC (Adenomatous Polyposis Coli) leads to unrestricted proliferation and even when only $10 \%$ of crypts are APC-deficient, several lesions and adenomas are recovered in the intestine. However, if these crypts are simultaneously mutant for APC and c-Myc, they are rapidly replaced by surrounding wild-type stem cells that repopulate the crypts, leading to complete rescue of pathological changes (Sansom et al., 2007). This, far from being a strict demonstration of Myc-mediated cell competition in mammalian tumourigenesis, represents a hint of the existence of mechanisms, dependent on the coexistence of cell populations with different Myc levels, able to restrain growth of cancerous cells.

\section{Conclusions}

It is quite clear that cancer cells are socially inadequate, because they subvert tissue and organ dynamics, like troubled teenagers in a respectable family. Primitive behaviours characterise their growth, such as an anxious search for food and an essential ability to break any barrier and, just as it happens in a respectable family, relatives are in most cases tolerant and, as a consequence, they are unavoidably overcome. In the most common oncogenic view of Myc-induced cell competition, cancer cells are able to grow at the expenses of their neighbours (Froldi et al., 2010; Menéndez et al., 2010; Neto-Silva et al., 2010; Ziosi et al., 2010). On the other hand, potentially harmful cells deficient in polarity genes can be eliminated early in development by the adjacent populations through apoptotic death induced by cell competition (Froldi et al., 2010) or intrinsic tumour suppression (Igaki et al., 2009) and do not participate in the formation of the final organ almost at all.

In regard to $\mathrm{lg} /$ mutant cells, Myc is the on-off switch that determines if they should live or die: grossly, lg/ cells expressing high levels of Myc live long and prosper and form tumours; Igl cells expressing low levels of Myc die (Froldi et al., 2010). However, absolute Myc levels are not actually informative; unless these latter are compared with those of the nearby cells, the fate of $\mathrm{gl}^{-}$ cells cannot be easily foreseen. So, the ancient sermon: No man is an island, mentioned in many well-known writings and movies, can be reworded to: No cell is an island. This is an acknowledged concept in tissue development and organ morphogenesis, but cancer has been instead long considered and cured as an autonomous disease, irrespective of the tissue it grew within. In the 
last decade, not only the microenvironment has begun to be taken into account in cancer biology, but also systemic responses have proved to participate in cancer growth and outcome. In Drosophila, many studies have investigated these aspects of tumourigenesis in different organs and contexts, which have been conveniently recapitulated in a recent review by Tipping and Perrimon (Tipping and Perrimon, 2013).

It has been recently shown that Igl cells forming tumours in the wing and in the eye imaginal discs cease to express the typical determinants of those tissues and switch to a primitive state; the experimental expression of these determinants is indeed capable of suppressing the tumourous phenotype and induce cell death (Khan et al., 2013), confirming that cancer cells need to subvert the genetic constraints of the tissue in order to break the morphological barriers imposed by the organ. This is quite interesting because, as mentioned above, Igl cells express very high levels of Myc in any context they succeed to form tumours, and Myc is one of the four genes that were found necessary for a human somatic cell to be reprogrammed into a pluripotent progenitor (Takahashi et al., 2007). Further studies in Drosophila could help elucidate the role of Myc in this important phenomenon.

Given the inactivation of the Hippo pathway observed in $\mid \mathrm{gl}$ clones, with the resulting nuclear translocation of the downstream effector Yorkie (Ménendez et al., 2010; Sun and Irvine, 2011; Khan et al., 2013), the high levels of Myc in the tumourous lgl clones are obviously due, at least in part, to its transcriptional activation; two studies indeed confirmed that Myc is a direct transcriptional target of Yorkie (Neto-Silva et al., 2010; Ziosi et al., 2010). Other pathways are possiby involved in increasing myc transcription and Myc protein accumulation in $/ g /$ mutant cells; as an example, in a recent paper the group of Kenneth Irvine identified the Ajuba (Jub) protein kinase, which is activated by the terminal MAPK downstream of the EGFR pathway, as an activator of Yorkie through its inhibitory binding to Warts and Salvador (Reddy and Irvine, 2013). Furthermore, it is well known that Myc protein stability is increased upon activation of the EGFR pathway (Prober and Edgar, 2002). Whether similar mechanisms are at work in lgl cells is currently under investigation in our lab.

The biochemical mechanisms for Yorkie activation in lgl-depleted cells has not been provided yet; genetic evidence however exists that in $\mid g l$ cells originated in the eye and wing discs, several upstream components of the Hippo pathway and proteins owing to different polarity complexes are mislocalised (Chen et al., 2010; Grzeschik et al., 2010; Ling et al., 2010; Robinson et al., 2010). But what is the temporal relationship between loss of cell polarity and hyperproliferation? Which one triggers the other? Or is it a chess game instead? It is thinkable that a tumour must reach a certain dimension in cell number before beginning to dictate new rules within the tissue; hyperproliferation is thus supposed to be the best opening move. Two studies performed in Drosophila have demonstrated that, during tumour progression, deregulation of the Hippo pathway signals back to the apical cortex inducing an increase in Crumbs and aPKC levels, thus promoting apical hypertrophy (Genevet et al., 2009; Hamaratoglu et al., 2009). A mild disruption of apical-basal cell polarity could thus trigger a partial deregulation of the Hippo pathway which, in turn, would increase the abundance of apical determinants so provoking an imbalance between apical and basal complexes that could translate into a structural collapse of the cell apical-basal axis. At this stage, Hippo pathway deregulation would become stronger and, in certain contexts, it could induce further tumourous phenotypes such as invasion and growth at secondary sites. Several studies in flies and mammals have indeed shown that the Hippo pathway is regulated by mechanical signals coming from cell membrane, cell junctions and cytoskeleton, conveyed to provide cells with positional information and spatial/social cues (reviewed by Schroeder and Halder, 2012). Moreover, since aPKC and Crumbs anisotropy has been involved in the formation of cellular and supracellular actomyosin cables (Röper, 2012) which function is, among others, to structure and maintain epithelial functional clusters and compartment boundaries during development, it is also possible that changes in abundance and localisation of these apical determinants during tumour growth disrupt actomyosin cables arrangement thus helping disorganise tissue architecture.

The function of Myc in all these processes remains largely unexplored. It is a matter of fact that Myc protein accumulation characterises the vast majority of Drosophila and human cancers, and that in experimental systems it is found responsible for the most part of the phenotypes induced by deregulation of the Hippo pathway in different organs and cell types (Ziosi et al., 2010; Reddy and Irvine, 2011; Ren et al., 2013); nevertheless, myc overexpression, also in combination with $d I A P 1$, is not able to rescue viability of yki mutant cells (Ziosi et al., 2010), suggesting that multiple levels of complexity must be taken into account when one is trying to dissect gene function in a cancer context. For this reason, the use of animal models in which several techniques combining cellular and developmental genetics are available can have a deep impact on cancer research.

\section{Acknowledgements}

Work in our laboratory is supported by the "Associazione Italiana di Ricerca sul Cancro (AIRC, IG 12093) and by the "Fondazione CaRisBO" (2011/0697). DG is supported by a Research Fellowship from Dipartimento di Farmacia e Biotecnologie, University of Bologna. We thank anonymous reviewers for useful comments, Patrizia Romani for critical reading of the manuscript and Fabrizio Pastori for help with graphics.

\section{References}

ALBIHN A, JOHNSEN J I and HENRIKSSON M A (2010). MYC in oncogenesis and as a target for cancer therapies. Adv Cancer Res 107: 163-224.

BADOUEL C, GARDANO L, AMIN N, GARG A, ROSENFELD R, LE BIHAN T and MCNEILL H (2009). The FERM-domain protein Expanded regulates Hippo pathway activity via direct interactions with the transcriptional activator Yorkie. Dev Cell 16: 411-420.

BAKER N E and LI W (2008). Cell competition and its possible relation to cancer Cancer Res 68: 5505-5507.

BEAUCHER M, GOODLIFFE J, HERSPERGER E, TRUNOVA S, FRYDMAN H and SHEARN A (2007a). Drosophila brain tumor metastases express both neuronal and glial cell type marker. Dev Biol 301: 287-297.

BEAUCHER M, HERSPERGER E, PAGE-MCCAW A and SHEARN A (2007b). Metastatic ability of Drosophila tumors depends on MMP activity. Dev Bio/303:625-634

BETSCHINGER J, MECHTLER K and KNOBLICH J A (2003). The Par complex directs asymmetric cell division by phosphorylating the cytoscheletal protein $\mathrm{Lgl}$. Nature 422: 326-330.

BETSCHINGER J, EISENHABER F and KNOBLICH J A (2005). Phosphorylationinduced autoinhibition regulates the cytoskeletal protein Lethal (2) giant larvae. Curr Biol 15: 276-282.

BILDER D, LI M and PERRIMON N (2000). Cooperative regulation of cell polarity and growth by Drosophila tumor suppressors. Science 289: 113-116. 
BILDERD (2004). Epithelial polarity and proliferation control: links from the Drosophila neoplastic tumor suppressors. Genes Dev 18: 1909-1925.

BRUMBY A M and RICHARDSON H E (2003). scribble mutants cooperate with oncogenic Ras or Notch to cause neoplastic overgrowth in Drosophila. EMBO J 22: 5769-5779.

BRUMBY A, SECOMBE J, HORSFIELD J, COOMBE M, AMIN N, COATES D, SAINT $\mathrm{R}$ and RICHARDSON H (2004). A genetic screen for dominant modifiers of a cyclin $\mathrm{E}$ hypomorphic mutation identifies novel regulators of S-phase entry in Drosophila. Genetics 168: 227-251.

CHEN CL, GAJEWSKI KM, HAMARATOGLU F, BOSSUYT W, SANSORES-GARCIA L, TAO C and HALDER G (2010). The apical-basal cell polarity determinant Crumbs regulates Hippo signaling in Drosophila. Proc NatlAcad SciUSA 107: 15810-15815.

CHEN C, SCHROEDER M C, KANGO-SINGH M, TAO C and HALDER G (2011). Tumor suppression by cell competition through regulation of the Hippo pathway. Proc Natl Acad Sci USA 109: 484-489.

CHEN F (2012). JNK-induced apoptosis, compensatory growth, and cancer stem cells. Cancer Res 72: 379-386.

CHO E, FENG Y, RAUSKOLB C, MAITRA S, FEHON R and IRVINE K D (2006). Delineation of a Fat tumor suppressor pathway. Nat Genet 38: 1142-1150.

CLAVERÍA C, GIOVINAZZO G, SIERRA R and TORRES M (2013). Myc-driven endogenous cell competition in the early mammalian embryo. Nature 500: 39-44. doi: 10.1038/nature12389.

CORDENONSI M, ZANCONATO F, AZZOLIN L, FORCATO M, ROSATO A, FRASSON C, INUI M, MONTAGNER M, PARENTI A R, POLETTI A et al., (2011). The Hippo transducer TAZ confers cancer stem cell-related traits on breast cancer cells. Cell 147: 759-772.

DOGGET K, GRUSCHE F A, RICHARDSON H E and BRUMBY A M (2011). Loss of the Drosophila cell polarity regulator Scribbled promotes epithelial tissue overgrowth and cooperation with oncogenic Ras-Raf through impaired Hippo pathway signaling. BMC Dev Biol 11: 57.

DONG J, FELDMANN G, HUANG J, WU S, ZHANG N, COMERFORD S A, GAYYED M F, ANDERS RA, MAITRAA, PAND (2007). Elucidation of a universal size-control mechanism in Drosophila and mammals. Cell 130:1120-1133.

DOW L E, BRUMBY, A M, MURATORE R, COOMBE M L, SEDELIES K A, TRAPANI J A, RUSSELL S M, RICHARDSON H E and HUMBERT P O (2003). hScrib is a functional homologue of the Drosophila tumour suppressor Scribble. Oncogene 22: 9225-9230.

DOW LE and HUMBERT P O (2007). Polarity regulators and the control of epithelial architecture, cell migration and tumorigenesis. Int Rev Cytol 262: 253-302.

DE LA COVA C, ABRIL M, BELLOSTA P, GALLANT P and JOHNSTON L A (2004). Drosophila Myc regulates organ size by inducing cell competition. Cell117:107-116.

FROLDI F, ZIOSI M, TOMBA G, PARISI F, GAROIA F, PESSION A and GRIFONI (2008). Drosophila lethal giant larvae neoplastic mutant as a genetic tool for cancer modeling. Curr Genomics 9: 147-154.

GALLANT P (2005). Myc, cell competition, and compensatory proliferation. Cancer Res 65: 6485-6487.

GATEFF E (1978). The genetics and epigenetics of neoplasms in Drosophila. Biol Rev Camb Philos 53: 123-168.

GENEVET A, POLESELLO C, BLIGHT K, ROBERTSON F, COLLINSON L M, PICHAUD F and TAPON N (2009). The Hippo pathway regulates apical-domain size independently of its growth-control function. J Cell Sci 122: 2360-2370.

GONT A, HANSON J E L, LAVICTOIRE $S$ J, PAROLIN D A E, DANESHMAND M, RESTALL I J, SOUCIE M, NICHOLAS G, WOULFE J, KASSAM A et al., (2013). PTEN loss represses glioblastoma tumor initiating cell differentiation via inactivation of Lgl1. Oncotarget 4: 1266-1279.

GRIFONI D, GAROIA F, SCHIMANSKI C C, SCHMITZ G, LAURENTI E, GALLE P R. PESSION A, CAVICCHI S and STRAND D (2004). The human protein Hugl-1 substitutes for Drosophila lethal giant larvae tumour suppressor function in vivo. Oncogene 23: 8688-8694.

GRIFONI D, GAROIA F, BELLOSTAP, PARISI F, DE BIASE D, COLLINA G, STRAND D, CAVICCHI S and PESSION A (2007). aPKCz cortical loading is associated with Lgl cytoplasmic release and tumor growth in Drosophila and human epithelia. Oncogene 26: 5960-5965.

GRZESCHIK N A, AMIN N, SECOMBE J, BRUMBY A M and RICHARDSON H E (2007). Abnormalities in cell proliferation and apico-basal cell polarity are separable in Drosophila lg/ mutant clones in the developing eye. Dev Bio/311: 106-123.
GRZESCHIK N A, PARSONS L, ALLOT M, HARVEY K F and RICHARDSON H E (2010). Lgl, aPKC and Crumbs regulate the Salvador/Warts/Hippo pathway through two distinct mechanisms. Curr Biol 20: 573-581.

HALDER G and JOHNSON R L (2011). Hippo signaling: growth control and beyond. Development 130: 9-22.

HAMARATOGLU F, GAJEWSKI K, SANSORES-GARCIA L, MORRISON C, TAO C and HALDER G (2009). The Hippo tumor-suppressor pathway regulates apicaldomain size in parallel to tissue growth. $J$ Cell Sci 122: 2351-2359.

HARIHARAN I K and BILDER D (2006). Regulation of imaginal disc growth by tumorsuppressor genes in Drosophila. Annu Rev Genet 40: 335-361.

HUANG J, WU S, BARRERA J, MATTHEWS K, PAN D (2005). The Hippo signaling pathway coordinately regulates cell proliferation and apoptosis by inactivating Yorkie, the Drosophila homolog of YAP. Cell 122: 421-434.

HUTTERER A, BETSCHINGER J, PETRONCZKI M and KNOBLICH J A (2006). Sequential roles of Cdc42, Par-6, aPKC, and Lgl in the establishment of epithelial polarity during Drosophila embryogenesis. Dev Cell 6: 845-854.

IGAKI T, PASTOR-PAREJA J C, AONUMA H, MIURA M and XU T (2009). Intrinsic tumor suppression and epithelial maintenance by endocytic activation of Eiger/ TNF signaling in Drosophila. Dev Cell 16: 458-465.

IGAKI T, PAGLIARINI R A and XU T (2006). Loss of cell polarity drives tumor growth and invasion through JNK activation in Drosophila. Curr Biol 16: 1139-1146.

JOHNSTONLA, PROBERDA, EDGARBA, EISENMANRN and GALLANTP (1999). Drosophila myc regulates cellular growth during development. Cell 98: 779-790.

KALLAY L M, MCNICKLE A, BRENNWALD P J, HUBBARD A L and BRAITERMAN L T (2006). Scribble associates with two polarity proteins, Lgl2 and Vanlg2, via distinct molecular domains. J Cell Biochem 99: 647-664.

KHAN S J, BAJPAI A, ALAM M A, GUPTA R P, HARSH S, PANDEY R K, GOELBHATTACHARYAS, NIGAMA, MISHRA and SINHAP (2013). Epithelial neoplasia in Drosophila entails switch to primitive cell states. Proc Natl Acad Sci USA 110: E2163-2172.

KLEZOVITCH O, FERNANDEZ T E, TAPSCOTT S J and VASIOUKHIN V (2004). Loss of cell polarity causes severe brain dysplasia in $L g / 1$ knockout mice. Genes Dev 18: 559-571.

KORSHUNOV A, SYCHEVA R and GOLANOV A (2006). Genetically distinct and clinically relevant subtypes of glioblastoma defined by array-based comparative genomic hybridization (array-CGH). Acta Neuropathol 111: 465-474.

KUPHAL S, WALLNER S, SCHIMANSKI C C, BATAILLE F, HOFER P, STRAND S, STRAND D and BOSSERHOFF A K (2006). Expression of Hugl-1 is strongly reduced in malignant melanoma. Oncogene 25: 103-110.

LEE C Y, ROBINSON K J and DOE C Q (2006). Lgl, Pins and aPKC regulate neuroblast self-renewal versus differentiation. Nature 439: 594-598.

LEE T and LUO L (2001). Mosaic analysis with a repressible cell marker (MARCM) for Drosophila neural development. Trends Neurosci 24: 251-254.

LEVYER R and MORENO E (2013). Mechanisms of cell competition: Themes and variations. JCB 200: 689-698.

LI W and BAKER N E (2007). Engulfment is required for cell competition. Cell 129 : 1215-1225.

LING C, ZHENG Y, YIN F, YU J, HUANG J, HONG Y, WUSAnd PAN D (2010). The apical transmembrane protein Crumbs functions as a tumor suppressor that regulates Hippo signaling by binding to Expanded. Proc Natl Acad Sci USA 107: 10532-10537.

LOLOFN, CASAS-TINTÓ Sand MORENOE (2012). Cell competition time line: winners kill losers, which are extruded and engulfed by hemocytes. Cell Rep 2: 526-539.

LU X, FENG X, MAN X, YANG G, TANG L, DU D, ZHANG F, YUAN H, HUANG Q, ZHANG $Z$ et al., (2009). Aberrant splicing of Hugl-1 is associated with epatocellular carcinoma progression. Clin Cancer Res 15: 3287-3296.

MCALLISTER S and WEINBERG RA (2010). Tumor-host interactions: a far-reaching relationship. J Clin Oncol 28: 4022-4028.

MENÉNDEZ J, PÉREZ-GARIJO A, CALLEJA M and MORATA G (2010). A tumorsuppressing mechanism in Drosophila involving cell competition and the Hippo pathway. Proc Natl Acad Sci USA 107: 14651-14656.

MORATA G and RIPOLL P (1975). Minutes: mutants of Drosophila autonomously affecting cell division rate. Dev Biol 42: 211-221.

MORENO E, BASLER K and MORATA G (2002). Cells compete for Decapentaplegic survival factor to prevent apoptosis in Drosophila wing development. Nature 
416: 755-759.

MORENO E and BASLER K (2004). dMyc transforms cells into super-competitors. Cell 117: 117-129.

MORENOE (2008). Is cell competition relevant to cancer? Nat Rev Cancer8: 141-147.

NETO-SILVA R M, DE BECO S and JOHNSTON L A (2010). Evidence for a growthstabilizing regulatory feedback mechanism between Myc and Yorkie, the Drosophila homolog of Yap. Dev Cell 19: 507-520.

NORMAN M, WISNIEWSKA K A, LAWRENSON K, GARCIA-MIRANDA P, TADA M, KAJITAM, MANO H, ISHIKAWAS, IKEGAWAM, SHIMADAT and FUJITAY (2012). Loss of Scribble cause cell competition in mammalian cells. J Cell Sci 125: 59-66.

OERTEL M, MENTHENAA, DABEVA M D and SHAFRITZ D A (2006). Cell competition leads to a high level of normal liver reconstitution by transplanted fetal liver stem/progenitor cells. Gastroenterology 130: 507-520.

OLIVER E R, SAUNDERS T L, TARLÉ SA and GLASER T (2004). Ribosomal protein L24 defect in belly spotand tail(Bst), a mouse Minute. Development 131:3907-3920.

PAGLIARINI R A and XU T (2003). A genetic screen in Drosophila for metastatic behavior. Science 302: 1227-1231.

PIETRAS K and ÖSTMAN A (2010). Hallmarks of cancer: Interactions with the tumor stroma. Exp Cell Res 316: 1324-1331.

PROBER D A and EDGAR B A (2002). Interactions between Ras1, dMyc, and dPI3K signaling in the developing Drosophila wing. Genes Dev 16: 2286-2299.

REDDY B V and IRVINE K D (2011). Regulation of Drosophila glial cell proliferation by Merlin-Hippo signaling. Development 138: 5201-5012.

REDDY B V and IRVINE K D (2013). Regulation of Hippo signaling by EGFR-MAPK signaling through Ajuba family proteins. Dev Cell 24:459-471.

REN F, SHI Q, CHENY, JIANG A, IPYT, JIANG H and JIANG J (2013). Drosophila Myc integrates multiple signaling pathways to regulate intestinal stem cell proliferation during midgut regeneration. Cell Res 23: 1133-1146. doi: 10.1038/cr.2013.101.

RHINER C and MORENO E (2009). Supercompetition as a possible mechanism to pioneer precancerous fields. Carcinogenesis 30: 723-728.

ROBINSON B S, HUANG J, HONG Y and MOBERG K H (2010). Crumbs regulates Salvador/Warts/Hippo signaling in Drosophila via the FERM-domain protein Expanded. Curr Biol 20: 582-590.

ROLLS M M, ALBERTSON R, SHIH H P, LEE C Y and DOE C Q (2003). Drosophila aPKC regulates cell polarity and cell proliferation in neuroblasts and epithelia. $J$ Cell Biol 163: 1089-1098.

RÖPER K (2012). Anisotropy of Crumbs and aPKC drives myosin cable assembly during tube formation. Dev Cell 23: 939-953.

RYOO H D, GORENC T and STELLER H (2004). Apoptotic cells can induce compensatory cell proliferation through the JNK and Wingless signaling pathways. Dev Cell 7: 491-501.

SANCHO M, DI-GREGORIO A, GEORGE N, POZZI S, SÁNCHEZ J M, PERNAUTE B and RODRÍGUEZTA (2013). Competitive interactions eliminate unfit embryonic stem cells at the onset of differentiation. Dev Cell 26: 19-30.

SANSOM O J, MENIEL V S, MUNCAN V, PHESSE T J, WILKINS J A, REED K R, VASS J K, ATHINEOS D, CLEVERS H and CLARKE A R (2007). Myc deletion rescues Apc deficiency in the small intestine. Nature 446: 676-679.

SCHIMANSKI C C, SCHMITZ G, KASHYAP A, BOSSERHOFF A K, BATAILLE F, SCHAFER S C, LEHR HA, BERGER M R, GALLE P R, STRAND S and STRAND D (2005). Reduced expression of Hugl-1, the human homologue of Drosophila tumour suppressor gene $\mathrm{lgl}$, contributes to progression of colorectal cancer. Oncogene 24: 3100-3109.

SCHROEDER M C and HALDER G (2012). Regulation of the Hippo pathway by cell architecture and mechanical signals. Semin Cell Dev Biol 23: 803-811.

SENOO-MATSUDA N and JOHNSTON L A (2007). Soluble factors mediate competitive and cooperative interactions between cells expressing different levels of Drosophila Myc. Proc Natl Acad Sci USA 104: 18543-18548.

SKOULOUDAKIK, PUETZM, SIMONS M, COURBARD J R, BOEHLKE C, HARTLEBEN B, ENGEL C, MOELLER M J, ENGLERT C, BOLLIG F et al., (2009). Scribble participates in Hippo signaling and is required for normal zebrafish pronephros development. Proc Natl Acad Sci USA, 106: 8579-8584.

SUN G and IRVINE K (2011). Regulation of Hippo signaling by Jun kinase signaling during compensatory cell proliferation and regeneration, and in neoplastic tumors. Dev Biol 350: 139-151.

TAKAHASHI K, TANABE K, OHNUKI M, NARITA M, ICHISAKA T, TOMODA K and YAMANAKA S (2007). Induction of pluripotent stem cells from adult human fibroblasts by defined factors. Cell 131: 861-872.

TAMORI Y, BIALUCHA C U, TIAN A G, KAJITA M, HUANG Y C, NORMAN M, HARRISON N, POULTON J, IVANOVITCH K, DISCH L et al., (2010). Involvement of Lgl and Mahjong/VprBP in cell competition. PLoS Biol:e1000422.

TERVONEN T A, PARTANEN J I, SAARIKOSKI S T, MYLLYEN M, MARQUES E, PAASONEN K, MOILANENA, WOHLFAHRT G, KOVANEN PE and KLEFSTROM $\mathrm{J}$ (2011). Faulty epithelial polarity genes and cancer. Adv Cancer Res 111: 98-161.

TIPPING M and PERRIMON N (2013). Drosophila as a model for context-dependent tumorigenesis. J Cell Physiol 229: 27-33. doi: 10.1002/jcp.24427.

THOMAS U, PHANNAVONG B, MULLER B, GARNER C C and GUNDELFINGER E D (1997). Functional expression of rat synapse-associated proteins SAP97 and SAP102 in Drosophila dlg-1 mutants: effects on tumor suppression and synaptic bouton structure. Mech Dev 62: 161-174.

TYLER D M, LI W, ZHUO N, PELLOCK B and BAKER N E (2007). Genes affecting cell competition in Drosophila. Genetics 175: 643-657.

VERGHESE S, WAGHMARE I, KWON H, HANES K and KANGO-SINGH M (2012). Scribble acts in the Drosophila fat-hippo pathway to regulate warts activity. PLOS One 7: e47173.

WAGNER EF and NEBREDAA R (2009). Signal integration by JNK and p38 MAPK patways in cancer development. Nat Rev Cancer 9: 537-549.

WODARZ A (2005). Molecular control of cell polarity and asymmetric cell division in Drosophila neuroblasts. Curr Opin Cell Biol 17: 475-481.

WODARTZ A and NÄTHKE I (2007). Cell polarity in development and cancer. Nat Cell Biol 9: 1016-1024.

WOODHOUSE E, HERSPERGER E, STETLER-STEVENSON W G, LIOTTA LA and SHEARN A (1994). Increased type IV collagenase in Igl-induced invasive tumors of Drosophila. Cell Growth Differ 5: 151-159.

WOODHOUSE E, HERSPERGER E and SHEARN A (1998). Growth, metastasis, and invasiveness of Drosophila tumors caused by mutations in specific tumor suppressor genes. Dev Genes Evol 207: 542-550.

ZIOSI M, BAENA-LÓPEZ L A, GRIFONI D, FROLDI F, PESSION A, GAROIA F, TROTTA V, BELLOSTA P, CAVICCHI S and PESSION A (2010). dMyc functions downstream of Yorkie to promote the supercompetitive behavior of Hippo pathway mutant cells. PLoS Genet 6: e1001140. 


\section{Further Related Reading, published previously in the Int. J. Dev. Biol.}

Apoptosis in Drosophila: compensatory proliferation and undead cells Francisco A. Martín, Ainhoa Peréz-Garijo and Ginés Morata

Int. J. Dev. Biol. (2009) 53: 1341-1347

The cellular and genetic bases of organ size and shape in Drosophila Antonio García-Bellido

Int. J. Dev. Biol. (2009) 53: 1291-1303

Cytoskeletal mechanisms responsible for invasive migration of neoplastic cells Jury M. Vasiliev

Int. J. Dev. Biol. (2004) 48: 425-439

http://dx.doi.org/10.1387/ijdb.041806jv

Requirement of Drosophila I(2)gl function for survival of the germline cells and organization of the follicle cells in a columnar epithelium during oogenesis.

C De Lorenzo, D Strand and B M Mechler

Int. J. Dev. Biol. (1999) 43: 207-217

http://dx.doi.org/10.1387/ijdb.10410900

Tumor suppressor and overgrowth suppressor genes of Drosophila melanogaster: developmental aspects

E Gateff

Int. J. Dev. Biol. (1994) 38: 565-590

http://dx.doi.org/10.1387/ijdb.7779680

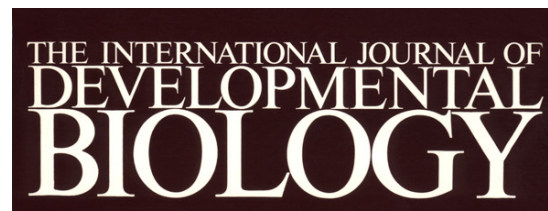

Volume 37 No. 1

March 1993
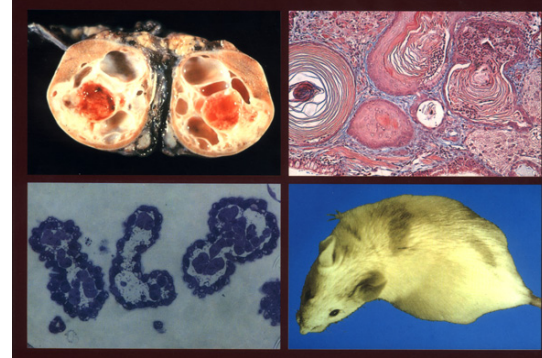

Developmental Aspects of Neoplasia
5 yr ISI Impact Factor $(2011)=2.959$

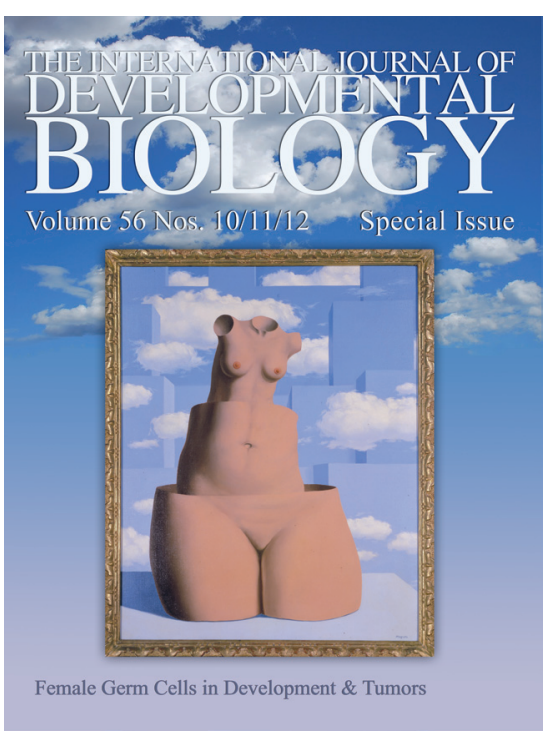

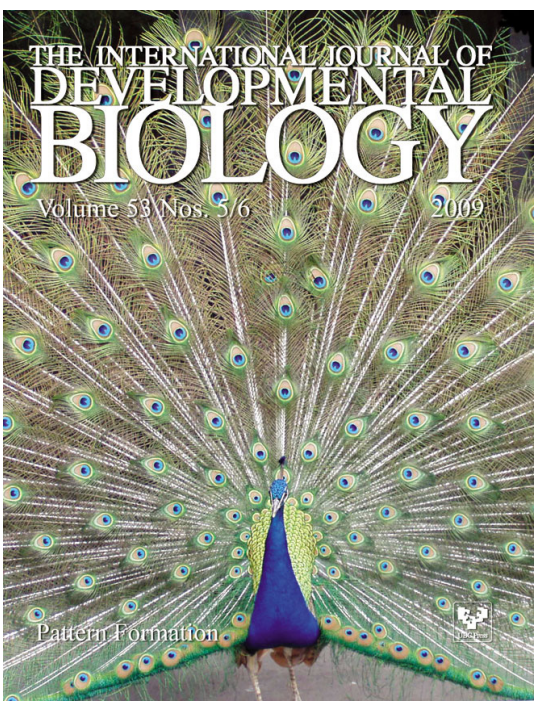

THE INTERNATIONAL JOURNAL OF DEVEIOPMENTAI

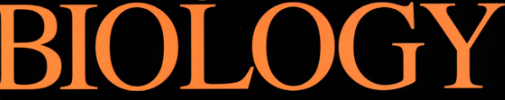

Volume 42 No. 3

Special issue

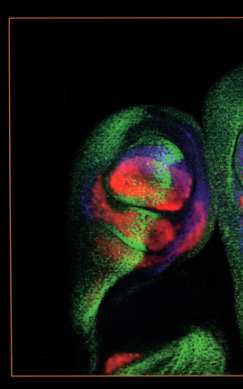

Developmental genetics of Drosophila 